\title{
GIS DATA COLLECTION FOR OIL PALM (DaCOP) MOBILE APPLICATION FOR SMART PHONE
}

\author{
A. F. Abdullah ${ }^{\text {a }}$ N. A. Muhadi ${ }^{\text {* }}$ \\ ${ }^{\text {a }}$ Department of Agricultural and Biological Engineering, Faculty of Engineering, Universiti Putra Malaysia - \\ ahmadfikri@upm.edu.com.my
}

KEY WORDS: Mobile application, Field data collection, Ganoderma, smart phone

\begin{abstract}
:
Nowadays, smart phone has become a necessity as it offers more than just making a phone call. Smart phone combines the features of cell phone with other mobile devices such as personal digital assistant (PDA) and GPS navigation unit that propel the popularity of smart phones. In recent years, the interest in mobile communication has been increased. Previous research using mobile application has been successfully done in varies areas of study. Areas of study that have been done are health care, education, and traffic monitoring. Besides, mobile application has also been applied in agricultural sector for various purposes such as plant pest risk management. In this study, mobile application for data collection on Ganoderma disease of oil palm has been successfully developed. The application uses several devices in a smart phone such as GPS, Wifi/ GPRS connection and accelerometer devices. The application can be installed in the smart phone and users can use the application while working on-site. The data can be updated immediately through their smart phones to the service. Besides, the application provides offline map so the user can be productive even though their network connectivity is poor or nonexistent. The data can be synced when the users online again. This paper presents an application that allows users to download features from a sync-enabled ArcGIS Feature Service, view and edit the features even when the devices fail to connect with any network connectivity while collecting data on-site.
\end{abstract}

\section{INTRODUCTION}

\subsection{Background}

Mobile phones are divided into three broad categories, which are basic phones, multimedia phones and smart phones (Chang et al., 2009). Nowadays, smart phone has become a necessity as it offers more than just making a phone call. Smart phone combines the features of cell phone with other mobile devices such as personal digital assistant (PDA) and GPS navigation unit that propel the popularity of smart phones. In recent years, the interest in mobile communication has been increased. Previous research using mobile application has been successfully done in various areas of study including health care, education, and traffic monitoring. Dala-Ali et al. (2011) reviewed the ways iPhone and Android can be applied during the working hours of the surgeons. In education sector, Chang et al. (2011) studied the impact of different teaching strategies including PDAs, smartphones, tablets and Internet on the learning performance of environment education. Structural frame of mobile learning system was discussed and constructed to obtain understandings of characteristics, development and technologies for mobile learning resource development (Guo et al., 2013).

Besides, mobile application has also been applied in agricultural sector. Baker et al. (2005) suggested several of technologies including mobile computing, GPS and telephone technologies to improve the management of pest outbreaks, fast transmission of data between field, lab and supervisory staff. Rafoss et al. (2010) developed an application that can be used in plant pest risk management. The study reported that the technology is successfully implemented to support the risk and crisis management in fighting of invasive plant disease using GPS devices in mobile phones. Embedded GPS is one of the factors that enhance the usage of mobile communication devices in field data collection. Field data collection is vital for adequate data analysis and decision-making. Traditionally, field data collection is done manually using pen and paper. The worker needs to change the format of the collected data into the desired format before doing any further analysis. It is time consuming and tedious task. Lwin and Murayama (2011) developed WebBased GIS system to demonstrate a real-time field data collection method for students using mobile phones. Besides, smart phone application has been used for forest sample plot where the application interprets imagery collected using camera in the smart phone before estimating the forest inventory attributes (Vastaranta et al., 2015).

Oil palm industry is the economic backbone of Malaysia. Being one of the biggest producers of palm oil and palm oil products, oil palm plantations have to ensure their production meets the market demands. One of the constraints in oil palm plantations is oil palm disease. Ganoderma diseases that are caused by the white rot fungus Ganoderma boninense are the major threat to sustainable oil palm plantation (Flood et al., 2000). It is important for the plantation management to detect the diseases early in order to control the disease risks and it plays important role to enhance the quality on managing a better and healthier plantation management. The mobile application is important as it provides the user more accurate data entry. When the workers have to scribble everything down manually, there are some possibilities of data error. They may forget to write down some data or skip some trees while collecting the information about the Ganoderma disease. Besides, the mobile application offers data input directly onsite to the office which saves the labor hours. By integrating the data from mobile application with GIS software, the disease trends which might not be easily identified, can be recognized. In addition, the application is easy to learn system to help the user to rapidly start getting

* Corresponding author 
work done with the system. It is a user-friendly mobile application to meet all level of education users. The application is simple and the system is easy to remember so that the users can still be able to return to it without having to learn all over again if they do not use it after certain period. This paper discusses the collection of field data on Ganoderma disease to see the trends of the disease in oil palm plantation by using mobile application during online or offline mode.

\section{METHODOLOGY}

The map of the oil palm plantation is created from IfSAR data. The oil palm trees in the plantation area are digitized using ArcGIS 10 which also acted as a database of the application. On the other hand, the application uses several devices and functionalities in a smart phone such as GPS, Wifi/ GPRS connection and accelerometer. The application was designed for mobile phones running on iOS 7.1 and above with at least 16GB storage and 32-bit processor. The software packages used for developing the application were ArcGIS Online and Xcode. Figure 1 shows the details of the application system for field data collection.

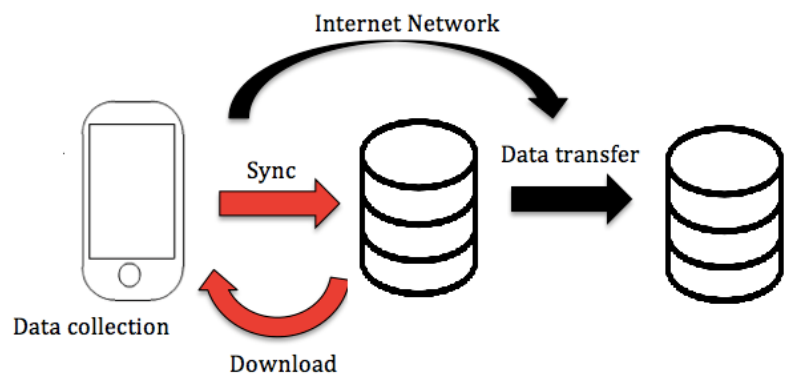

Figure 1. Data framework of the application

\subsection{ArcGIS Online}

ArcGIS Online provides the platform to create interactive web maps and applications that can be shared with anyone. ArcGIS Online helps in accessing the user's content in the easiest way. In this study, the map of oil palm plantation is uploaded in the ArcGIS Online to be retrieved by the Xcode for further analysis. ArcGIS can be used to manage inspections of the oil palm diseases. The users can be able to collect and retrieve up-to-date maps and important information in the field. As the users inspected the disease, they can send the reports directly to update the ArcGIS map in the office.

ArcPad is mobile field mapping and data collection software that was designed for GIS professionals. It has the capabilities for capturing, editing and displaying geographic information efficiently. Arcpad is part of an enterprise GIS solution and integrates directly with ArcGIS for Desktop and ArcGIS for Server.

Data Collection for Oil Palm (DaCOP) mobile application on the other hand is a custom mapping application to meet specific business needs. It has the ability to embed ArcGIS maps by using services from ArcGIS Online. DaCOP is developed for the collection of field data on Ganoderma disease. DaCOP is a very basic mobile application that is specially created for the workers in the plantation. The workers can easily use the application without the need for any specific skills so that all people from any level of education can use it with ease.

\subsection{Xcode}

Xcode is an Integrated Development Environment (IDE) developed by Apple used for developing applications and softwares for OS X and iOS. The Xcode uses an Objective- $\mathrm{C}$ language to do the commands. Xcode contains hundred of powerful features such as Xcode IDE, Objective-C compilers, iOS Simulator and the latest OS X and iOS SDKs. Graphical User Interface (GUI) is constructed using Interface Builder, which is a part of the Xcode. Xcode provides interface design, coding, testing and debugging in one workflow. The applications can be tested and deployed on iOS device after the developer successfully registered in Apple's iOS Developer Program.

\section{RESULT}

The application developed is called DaCOP. Before launching the application, user needs to ensure that the location services are switched on. Besides, the device needs a network connection to display the features from an ArcGIS Feature service properly. The application begins by choosing the program from the application menu. The application will be able to do the following operations:

1. Displaying description of the point features

2. Editing the attributes of the point features

3. Adding new point features

4. Deleting existing point features

5. Recording the level of Ganoderma disease

6. Recording notes with a text field where a textual description can be typed in

7. Recording dates of modifying point features in field

8. Syncing edits when online

\subsection{Operation of the mobile application}

The device needs a network connection to display the features from an ArcGIS Feature service properly. The application begins by choosing the program from the application menu. The application is in "Live Data" mode when startup.

The first step user needs to do after the application is started is to select the map for the field that they want to update about the Ganoderma disease. The user will be asked whether the application is allowed to use user's current location. Once the map has been loaded, it will display the point features that have been digitized and the current location, if the user allows the application to use the current location. The user can tap on any feature to view the properties of each of the point features in a popup. The description of the point features can be edited by clicking the 'Edit' button. Figure 2 shows the screenshots of the features that displayed on the screen and the description of one of the point features.

Date, level of Ganoderma disease and additional notes can be recorded using this application. The notes-field is created for the workers to leave any comments about the trees. For example, if the worker finds that there is a tree that shows different symptoms of disease, he can write the comments so that a prompt action can be done to control the risk. Besides, the existing point features can also be deleted and new point features can be added easily. Any edits that the user makes while in "Live" mode are updated immediately to the service. Figure 3 shows the screenshots of the process of recording date of fieldwork and the applying edit process. 


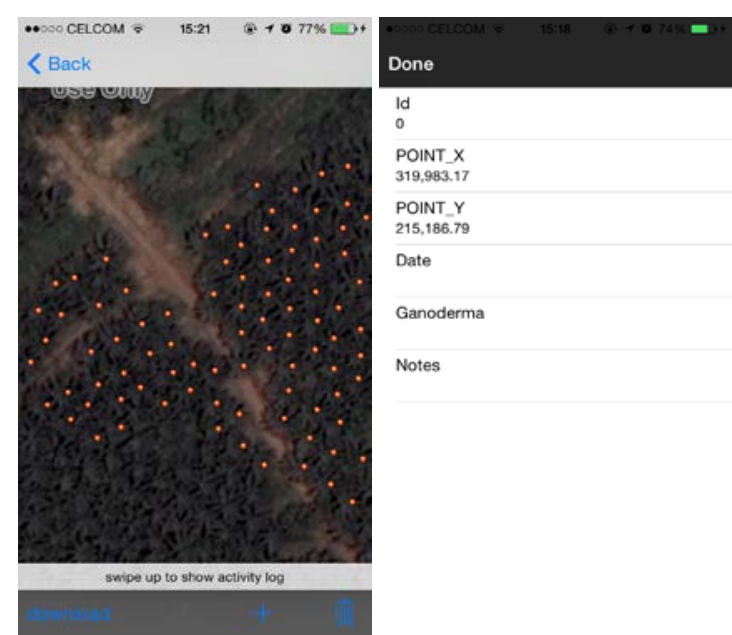

Figure 2. Screenshots of points features that displayed on the screen and the description of one of the point features.

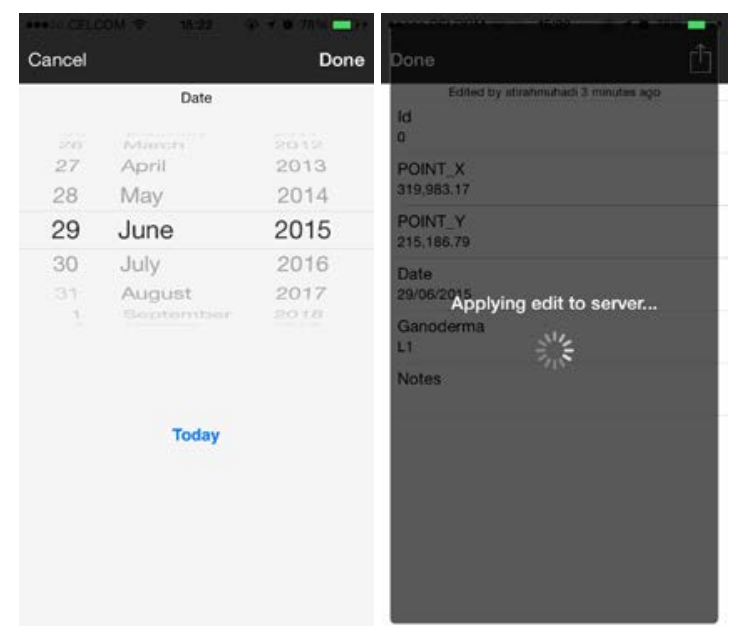

Figure 3. Sreenshots of recording the date of data collection and saving the edits to the server

If there is no network connection in the study area, the user can tap the 'download' button on the toolbar to download the features to the device. By downloading the features, the application is now changed into "Local Data" mode where the map display features from the replica geodatabase on the device. The user can view information and edit the features without worrying about the poor network connectivity. Any editing during offline are held in local geodatabase. They are displayed as a badge over the 'Sync' button on the toolbar. When the user is connected to a network, the user can tap the 'Sync' button to synchronize the changes that have been made during offline mode. The edits will be updated to the service. After the sync completes, the user can continue making edits in "Local" mode and synchronize again or tap the 'switch to live' button to start viewing live feature data from the service. The local geodatabase is left intact or the user can tap the 'Delete' button to delete all local geodatabase that have been created. Figure 4 shows the screenshots of the application when downloading process during offline mode and the synchronizing the changes that have been made during offline mode.
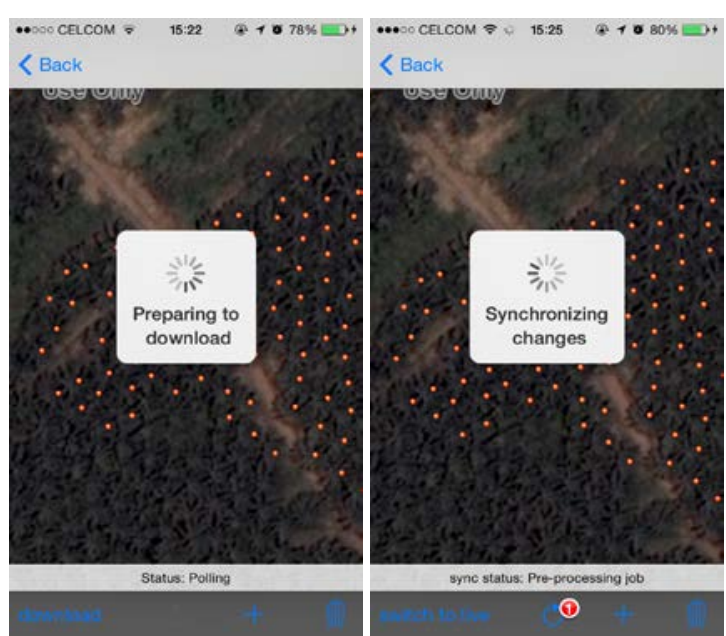

Figure 4. Screenshots of downloading and synchronizing process

\section{CONCLUSION}

This paper introduced an application for field data collection using a smart phone to see the trend of Ganoderma disease in oil palm plantation. All survey data are collected and stored in ArcGIS feature service. After field data collection has been finished, the user can download the updated data in the office. The user needs to login into ArcGIS Online and export the features file to shapefile. Further analysis can be done using ArcGIS 10. The application can be used in "Live Data" mode where user is editing the live data and also the "Local" mode where any editing during offline are held in local geodatabase and updated during the synchronize process when the network is available. The application can help in solving problem regarding the network connectivity in plantation area. Although the mobile application has been successfully developed for field data collection, there are still several possibilities for improvement for a better result for example verification of location for further analysis.

\section{REFERENCES}

Baker , R., Cannon, R., Bartlett, P., \& Barker, I. (2005). Novel strategies for assessing and managing the risks posed by invasive alien species to global crop production and biodiversity. Annals of Applied Biology 146 , 177-191.

Chang, C.-S., Chen, T.-S., \& Hsu, W.-H. (2011). The study on integrating WebQuest with mobile learning for environmental education. Computer and Education 57 , 1228-1239.

Chang, Y., Chen, C., \& Zhou, H. (2009). Smartphone for mobile commerce. Computer standards and interfaces 31 , 740747.

Dala-Ali, B., Lloyd, M., \& Al-Abed, Y. (2011). The uses of the iPhone for surgeons. The Surgeons .

Flood, J., O'Grady, E., Turner, P., \& O'Grady, E. (2000). The spread of Ganoderma from its infective sources in the field and its implications for management of the disease in oil palm. In J. Flood, P. Bridge, \& M. Holderness, Ganoderma. Disease of Perennial Crops (pp. 101-112). Wallingford, UK: CABI Publishing. 
Guo, L., Fu, Y., Yin, X., Yuan, M., Zhang, F., \& Gao, J. (2013). Application of Mobile Learning System in Operating System Course. Communication and Network , 157-160.

Hushiarian, R., Yusof, N., \& Dutse, S. (2013). Detection and control of Ganoderma boninense: strategies and perspectives. SpringerPlus , 2:555.

Lwin, K., \& Murayama, Y. (2011). Web-based GIS System for Real-Time Field Data Collection Using a Personal Mobile Phone. Journal of Geographic Information System , 382-389.

Rafoss, T., Sælid, K., Sletten, A., Gyland, L., \& Engravslia, L. (2010). Open geopsatial technology standards and their potential in plant pest risk management-GOS-enabled mobile phones utilising open geospatial technology standards Web Feature Service Transactions support the fighting of fire blight in Norway. Computers and Electronics in Agriculture , 336340 .

R. H. V. Corley, \& P. B. H. Tinker. (2003). Vegatative Propagation and Biotechnology. In The Oil Palm (pp. 201-215). John Wiley \& Sons.

Vastaranta , M., Latorre, E., Luoma , V., Saarinen, N., Holopainen , M., \& Hyyppä , J. (2015). Evaluation of a Smartphone App for Forest Sample Plot Measurements. Forests , 6 (4), pp. 1179-1194. 